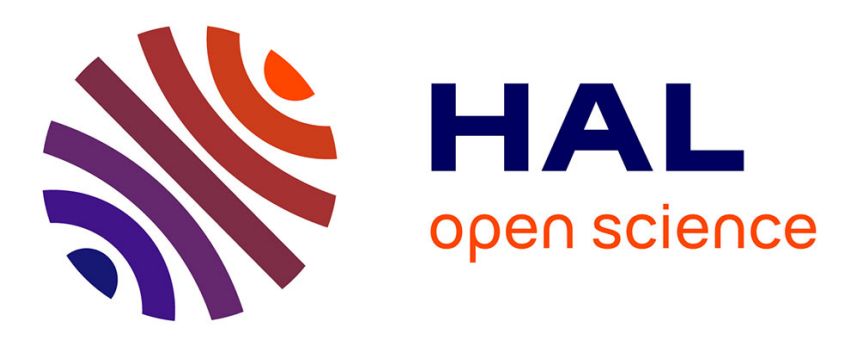

\title{
A new denoising methodology to keep the spatial resolution of IR images equal to 1 pixel
}

\author{
G. Corvec, Eric Robin, Jean-Benoit Le Cam, Jean-Christophe Sangleboeuf, \\ Philippe Lucas
}

\section{- To cite this version:}

G. Corvec, Eric Robin, Jean-Benoit Le Cam, Jean-Christophe Sangleboeuf, Philippe Lucas. A new denoising methodology to keep the spatial resolution of IR images equal to 1 pixel. Annual Conference and Exposition on Experimental and Applied Mechanics, 2017, Jun 2017, Indianapolis, United States. pp.21-27, 10.1007/978-3-319-62899-8_4. hal-01695487

\section{HAL Id: hal-01695487}

\section{https://hal-univ-rennes1.archives-ouvertes.fr/hal-01695487}

Submitted on 16 May 2020

HAL is a multi-disciplinary open access archive for the deposit and dissemination of scientific research documents, whether they are published or not. The documents may come from teaching and research institutions in France or abroad, or from public or private research centers.
L'archive ouverte pluridisciplinaire $\mathbf{H A L}$, est destinée au dépôt et à la diffusion de documents scientifiques de niveau recherche, publiés ou non, émanant des établissements d'enseignement et de recherche français ou étrangers, des laboratoires publics ou privés. 


\title{
A New Denoising Methodology to Keep the Spatial Resolution of IR Images Equal to 1 Pixel
}

\author{
Guillaume Corvec, Eric Robin, Jean-Benoît Le Cam, Jean-Christophe Sangleboeuf, and Pierre Lucas
}

\begin{abstract}
This paper proposes a noise suppression methodology to improve the spatio-temporal resolution of infrared images. The methodology is divided in two steps. The first one consists in removing the noise from the temporal signal at each pixel. In the second step, the residual offset is identified by considering thermal images for which no mechanical loading is applied. In this case, the temperature variation field is homogeneous and the value of temperature variation at each pixel is theoretically equal to zero. The method is first tested on numerical images. The results demonstrate that this approach permits to keep the spatial resolution of infrared images equal to 1 pixel. The methodology is then applied to characterize thermal activity of a defect at the surface of inorganic glass submitted to cyclic mechanical loading.
\end{abstract}

Keywords Infrared thermography $\bullet$ Denoising $\bullet$ Experimental mechanics $\bullet$ Soda lime glass $\bullet$ Indentation

\subsection{Introduction}

Thermal and calorimetric effects accompanying the deformation of materials are widely studied in literature to investigate thermomechanical couplings, fatigue and failure, non-exhaustively. Infrared thermography has proved to be a relevant technique for studying engineering materials such as steel, aluminum and composites. Experiments in this field consist in applying a mechanical loading and in measuring the temperature field induced at the material surface using an infrared camera. Temperature variation field is generally processed from temperature field to determine hydrostatic stress field by using thermoelastic stress analysis (TSA) [1], to investigate calorimetric response of materials or to access mechanical dissipation [2]. The results obtained provide information of importance for the understanding of deformation and damage mechanisms such as Luder's bands [3], fatigue [4, 5] strain localization [6] or strain-induced crystallization [7, 8]. In such conditions noise pollution does not alter significantly the measured temperature variation field and can be removed with the help of non-uniformity [9] correction of the infrared detector combined with a spatio-temporal filtering process. If the signal-to-noise ratio of infrared images in terms of temperature variation becomes low, processing infrared images is more complicated. Recent work has been carried out on this topic to characterize temperature variation gradients induced during a cyclic three points bending test applied to soda lime glass [10] and during cyclic compression test applied to a chalcogenide glass disk with a hole [11]. It is all the more complicated if higher gradients are induced during the mechanical loading. For example in the imprint zone after identation process [12], the use of an average filter in these conditions can smooth or remove the thermal activity. The present study aims at proposing a methodology to significantly improve the spatio-temporal resolution of thermal images in challenging conditions.

G. Corvec • E. Robin $(\varangle)$ • J.-B. Le Cam • J.-C. Sangleboeuf

Université de Rennes 1, Institut de Physique UMR 6251, CNRS/Université de Rennes 1, Campus de Beaulieu,

Bât. 10B, 35042, Rennes Cedex, France

e-mail: eric.robin@univ-rennes1.fr

P. Lucas

Arizona Materials Laboratory, 4715 East Fort Lowell Rd, Tucson, AZ 85712, USA 


\subsection{Image Processing Methodology}

After performing the Non Uniformity Correction [13,14] and once the mechanical tests starts and infrared images are stored, image denoising algorithms consist classically in applying a spatio-temporal filtering: one dimension in time, two dimensions in space. In this case, the spatial resolution cannot be a priori equal to 1 pixel. This is why we propose to perform image processing in two steps. At first, images are filtered only temporally (at this step1 the user can use any type of filter) and the second step consists in spatial treatment of images. We propose to use one way of investigation based on the thermodynamic principle that if no mechanical loading is applied, no temperature variation can be observed. Typically, for images stored just before starting the mechanical test, the temperature variation field must be homogeneous and equal to zero. Therefore, residual offsets can be identified from these images, and removed for each thermal pixel. In practice the process leading to residual offset removing was performed by applying the following processing scheme with Matlab software:

$$
M_{s}(x, y)=I_{\text {step } 1}\left(x, y, t=t_{0}\right)-I_{\text {step } 1}\left(x=x_{0}, y=y_{0}, t=t_{0}\right)
$$

where $\mathrm{M}_{\mathrm{S}}(\mathrm{x}, \mathrm{y})$ is the matrix of background shifting. Its components give the difference between the value at the reference pixel in reference image $I_{\text {step } 1}(x, x, t=t 0)$, which coordinates are $i 0$ and $j 0$, and the value at all the other ones. t0 is the time corresponding to the first image of the infrared movie. At t0, the value of temperature variation must be equal to zero at any pixel, since no mechanical loading is applied. Istep1 denotes the infrared image at step 1, meaning after the temporal filtering.

\subsection{Numerical Evaluation of the Proposed Methodolgy}

\subsubsection{Noised Numerical Image Construction}

The procedure consists in comparing anoriginal numerical noised image and its denoised version. However we must generate representative synthetic noise. In the case of infrared thermography, noise is due to two phenomena. The first one corresponds to photoelectric conversion and interference of signal processing circuits [15]. The second one is induced by experimental conditions, typically convection, radiations and image background. To avoid the development of models taking into account such phenomena, the noise was extracted experimentally from a repeatability test. This repeatability test was then performed at ambient temperature with a black body. The repeatability test consists in measuring the stabilized and homogeneous temperature field at the surface of a black body. Each infrared detector of the camera therefore provides a value of temperature that oscillates around the temperature of the black body. Consequently, extracting the noise means subtracting the average value of the corrupted signal to itself for each pixel. This enabled us to obtain the temporal evolution of the noise generated by the infrared camera considered in this study. The extracted experimental noise was then added to synthetic images. As the goal of this study is to keep 1 pixel spatial resolution after noise suppression, synthetic images without noise simulate local thermal activity of patterns "X", "O" and "+" with a width set to 1 pixel (Fig. 4.1).

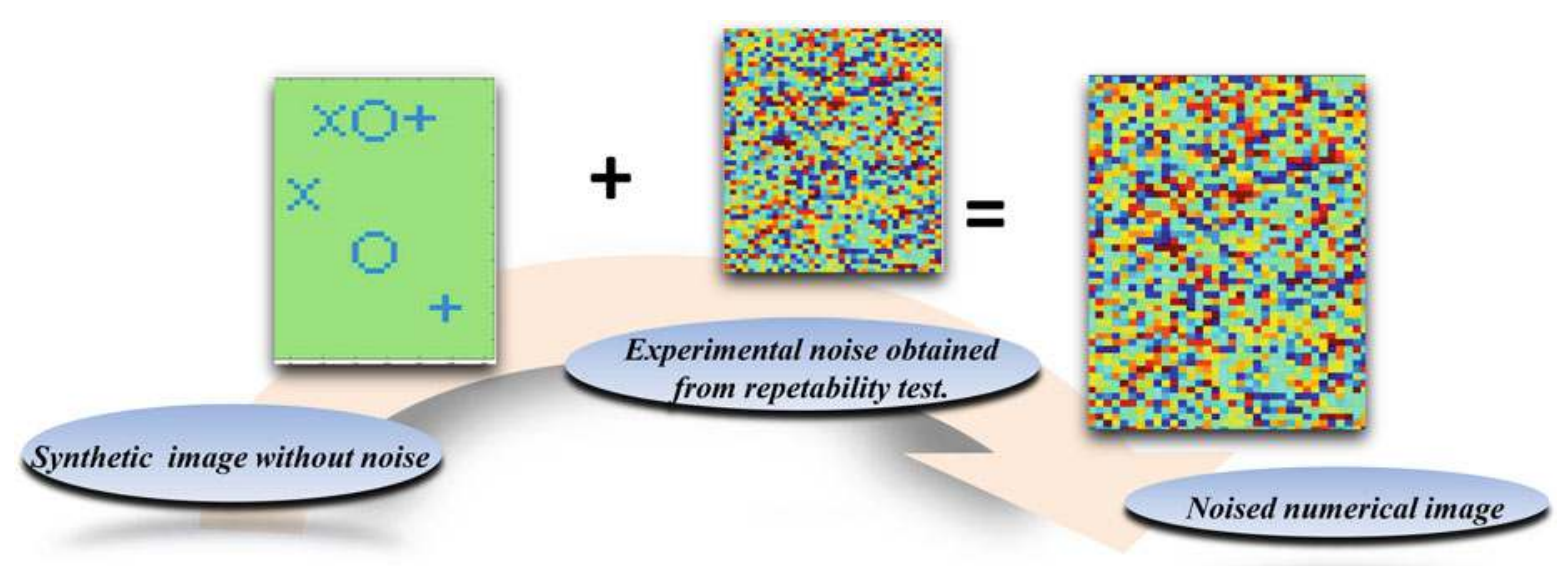

Fig. 4.1 Generation of numerical images 
The thermal activity of these patterns, denoted $\mathrm{T}_{\mathrm{swn}}$ evolved sinusoidally according to the following equation:

$$
T_{s w n}(x, y, t)=A \cos \left(\frac{2 \pi}{p}\left(t-t_{0}\right)\right)+B
$$

where A, B and p are amplitude modulation, offset and signal period, respectively. Such signal enables us to simulate thermal response of material under cyclic loading conditions. The signal amplitude modulation A was chosen to be equal to 0.05 , i.e. close to temperature variation amplitude found experimentally in a previous study dealing with inorganic glass [10]. $t$ corresponds to the image number and $t_{0}$ corresponds to the value chosen at the beginning of thermal activity. The period $p$ corresponded to 200 frames and is related in practice to the loading frequency.

\subsubsection{Denoising of Numerical Noised Images with the Proposed Method}

Figure 4.2 presents result obtained with a spatio-temporal approach. More precisely a $3 \times 3 \times 41$ average filter.

This filter is the smallest spatial one. It should be noted that this type of filter has previously been used for the detection of thermal activity in soda lime glasses [10]. It appears clearly that patterns are smoothed: crosses and diagonal lines are not distinguishable anymore. The spatial resolution is significantly altered by such a filter. Results clearly show that this type of basic filtering is not suitable to process low temperature variations combined with high temperature variation gradients. The objective is to show that even with basic temporal filters used during the first step, our methodology provides promising results in terms of spatial resolution. Denoising methodology was evaluated with these three filters:

- Average filter: In our case, a preliminary observation of thermal signal was carried out to determine a suitable kernel size which has to be lower than a quarter of the signal period. This kernel size leads to a filtered signal with sufficient modulation amplitude. Here, the kernel size was set at 41 images.

- Fitting with a polynomial form: Here, to avoid any oscillation due to noise, polynomial degree was set to 3 and the kernel size was chosen with respect to the period size, typically one-quarter of the signal period. Here, the kernel size was set at 61 images.

- Short time Fourier Transform: For each temporal signal, i.e. at each pixel, the maximum STFFT magnitude is determined. The cut-off value corresponds to the higher value of maximum STFFT magnitude field. Here, it is equal to 0.019 and the kernel size was set at 201 images.
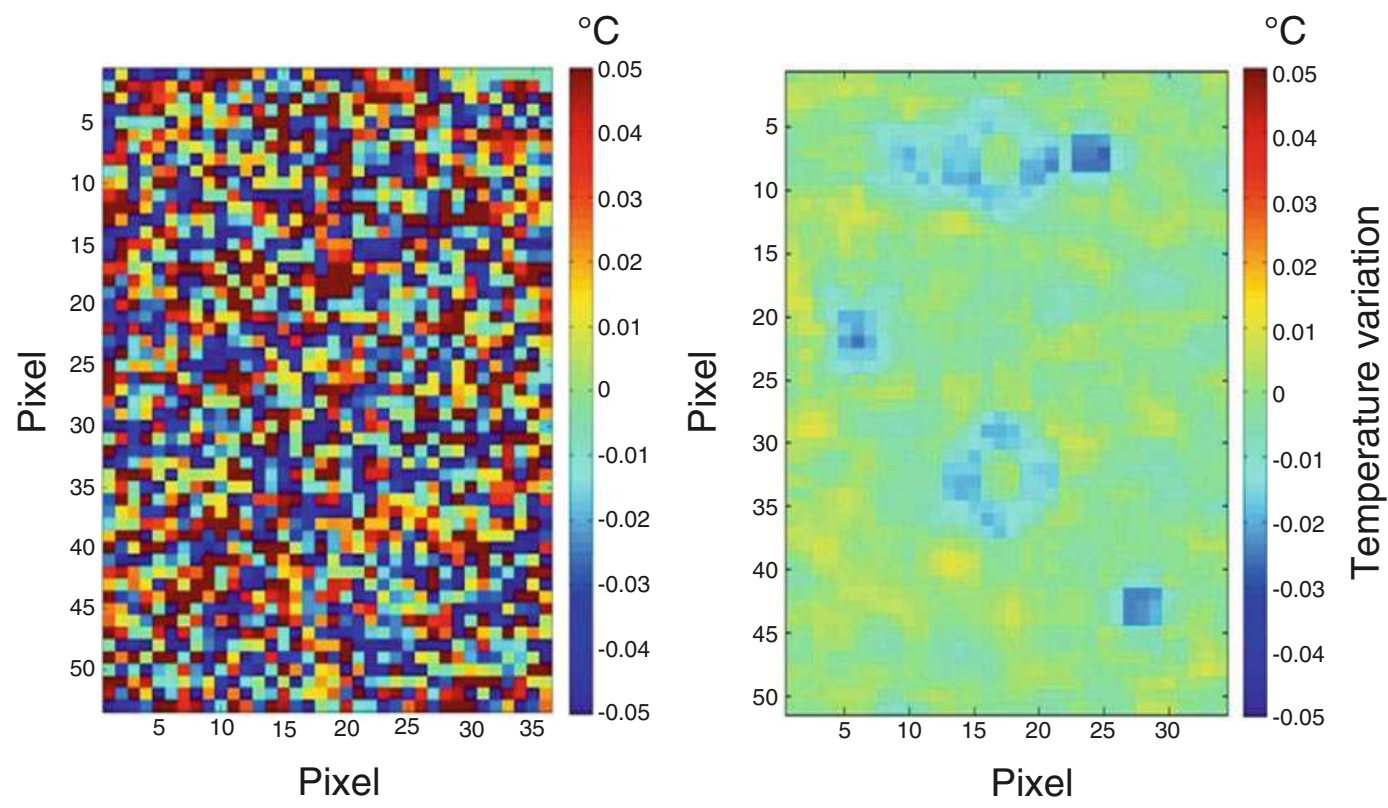

Fig. 4.2 Result obtained with a spatio_temporal approach $(3 \times 3 \times 41)$ 

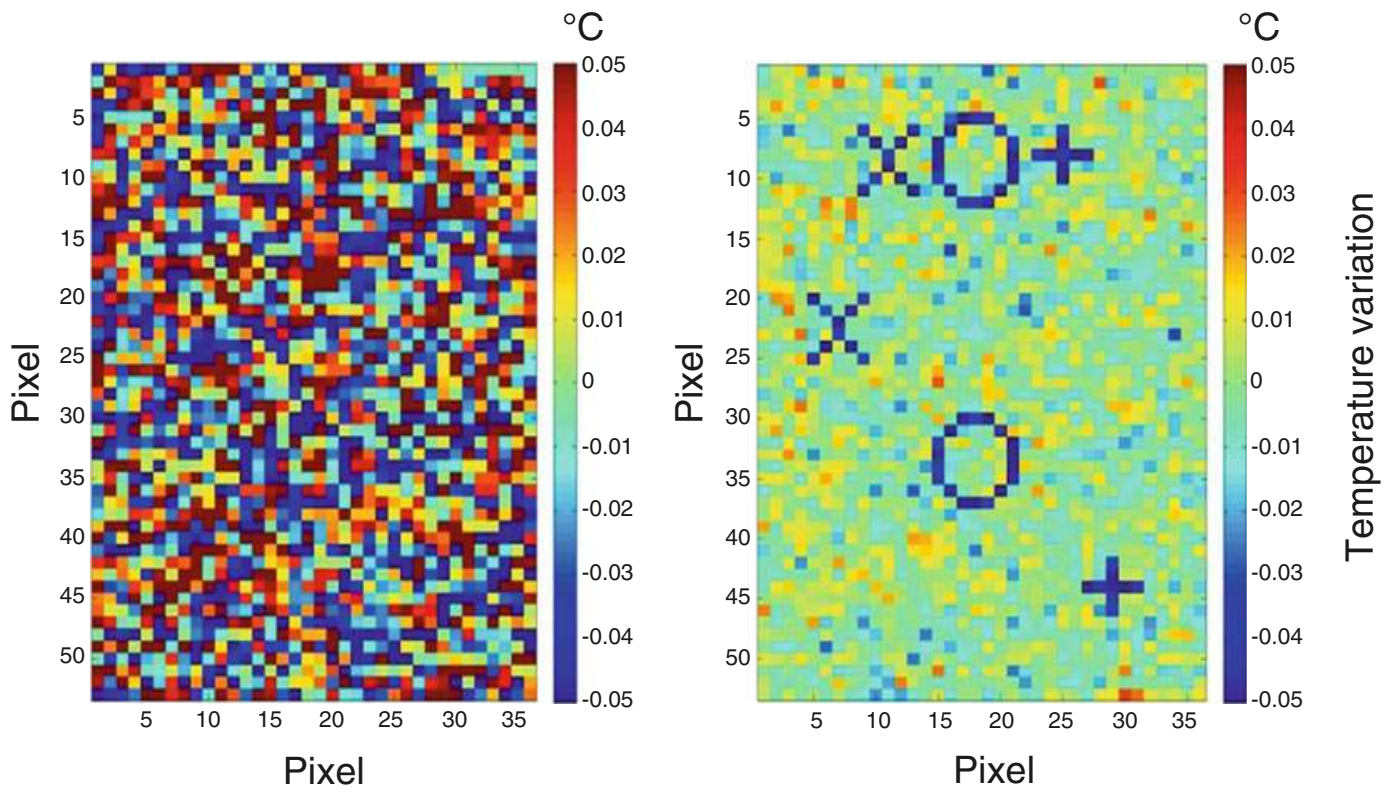

Fig. 4.3 Result obtained with an average filter during first step
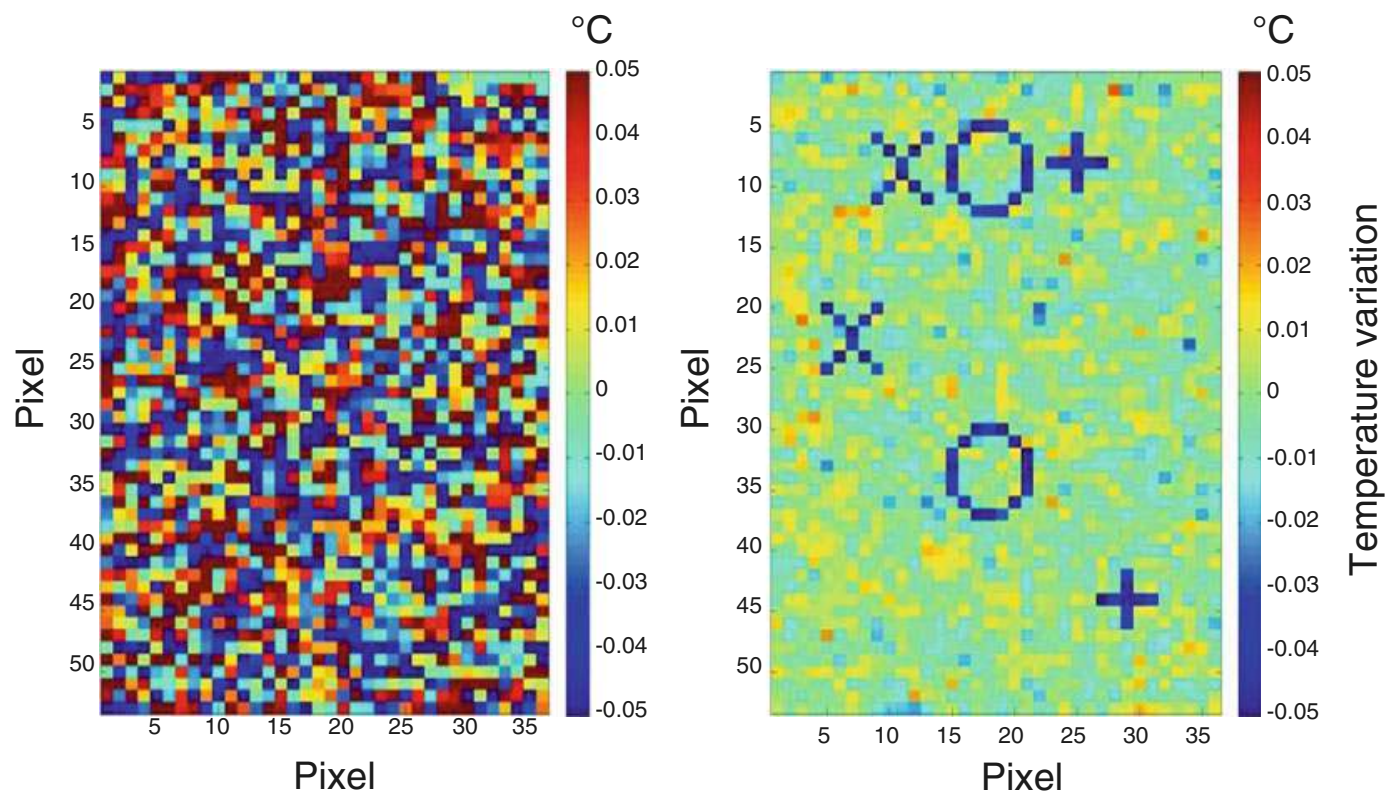

Fig. 4.4 Result obtained with a fit filter during first step

Figures 4.3, 4.4, and 4.5 gives results obtained by applying the background shifting after average, fit and STFFT temporal filtering, respectively. The pattern shape ("X", "O" and "+") is clearly retrieved. This demonstrates that this filtering methodology preserves the full spatial resolution of infrared images even with basic temporal filters. Nevertheless, even with the background shifting, thermal images still appear noisy after the fit filter (Figs. 4.2 and 4.3). It is due to oscillations induced by fit and average filters. In this paper, temporal filters used are basic ones. It should be noted that if the temporal filter used is more efficient and leads to very low oscillation amplitudes, the background shifting is the equivalent of removing fixed-pattern noise (FPN) [16]. The difference lies in the fact that classically FPN has a spatial structure [17-23], which is not the case here. 

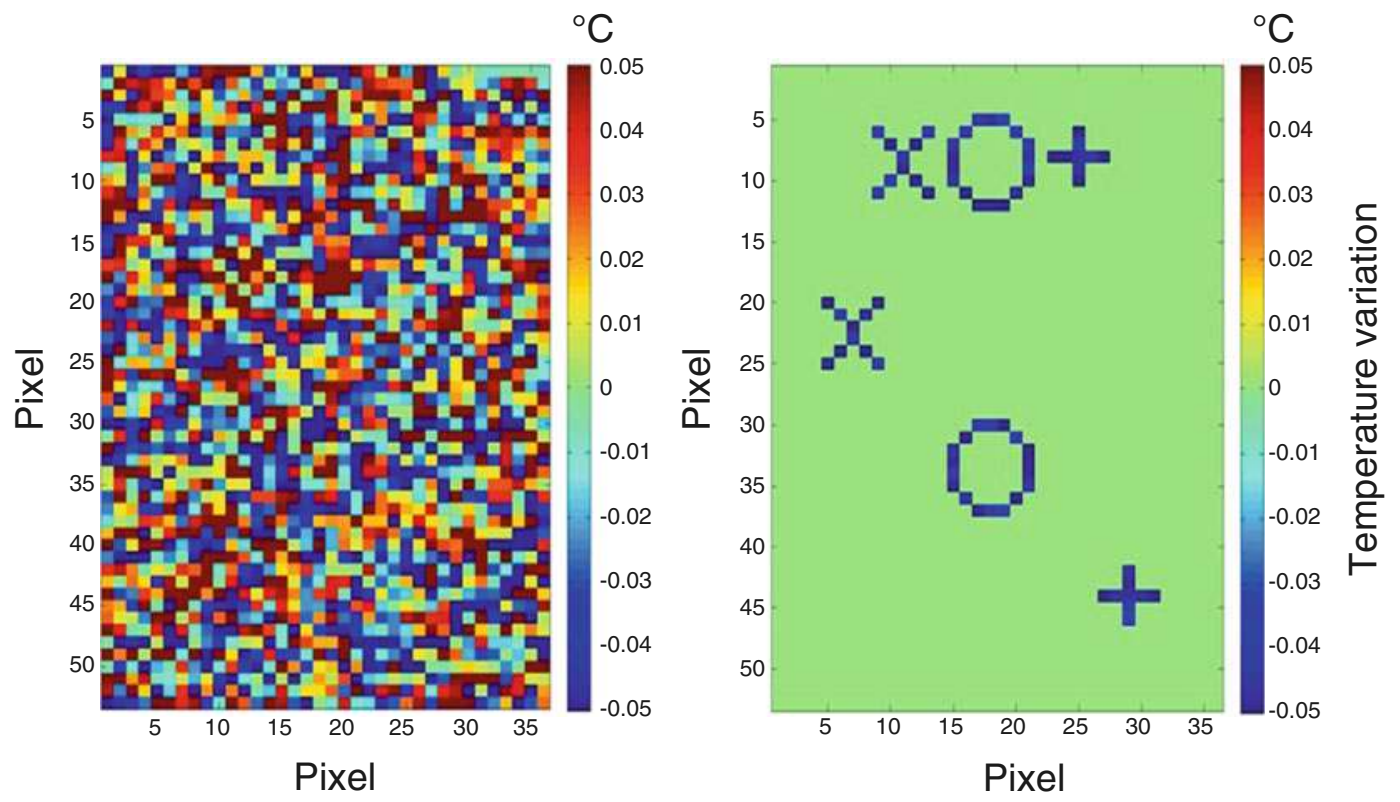

Fig. 4.5 Result obtained with a STFFT filter during first step

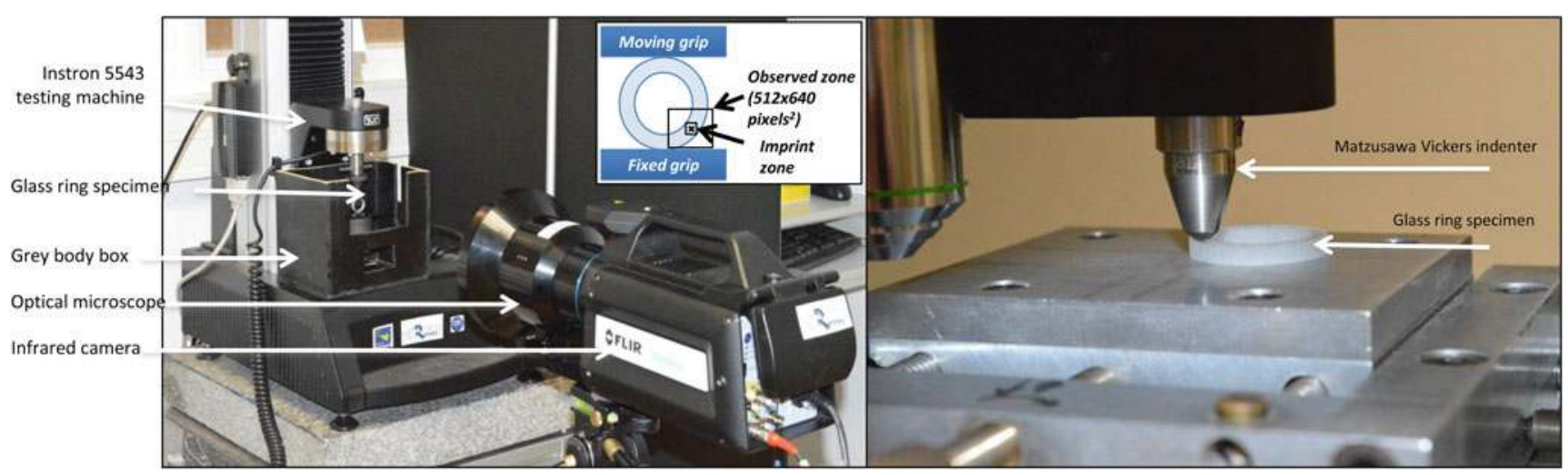

Fig. 4.6 Experimental setup

\subsection{Experimental Validation: Detection of Thermal Activity Along the Chips Border After Indentation}

\subsubsection{Experimental Set-Up}

The mechanical tests performed were based on the Brasilian test. In the case of the Brazilian test the specimen geometry is a disk while it is a ring in the present study. It is submitted to cyclic compression loading by means of a 5543 Instron testing machine. An overview of the experimental setup is given in Fig. 4.6.

The signal shape was sinusoidal. The minimum and the maximum values of the force were $-7 \mathrm{~N}$ and $-70 \mathrm{~N}$, respectively. This corresponded to a displacement of $0.07 \mathrm{~mm}$. The sample was submitted to fifteen cycles at a frequency equal to $3.6 \mathrm{~Hz}$. Specimen geometry corresponded to a ring of soda lime glass. The specimen was $20 \mathrm{~mm}$ in external diameter, $13 \mathrm{~mm}$ in internal diameter and $2.8 \mathrm{~mm}$ in thickness. The ring was cut with a water jet cutting machine. An imprint was made at its surface with the help of a Matzusawa Vickers indenter. This is illustrated in Fig. 4.6. The indentation load was set to $50 \mathrm{~N}$. The resulting surface defect was observed with a VHX Keyence microscope. Temperature measurements were performed at ambient temperature using the same X6540sc FLIR camera than that used for extracting the noise (section B). It features a focal plane array of $640 \times 512$ pixels and detectors with a wavelength range of 1.5-5.1 $\mu \mathrm{m}$. The integration time was equal to $1,000 \mu \mathrm{s}$ and the acquisition frequency was set at $200 \mathrm{fps}$. The resolution is equal to $20 \mathrm{mK}$ at $25^{\circ} \mathrm{C}$, which is approximately 

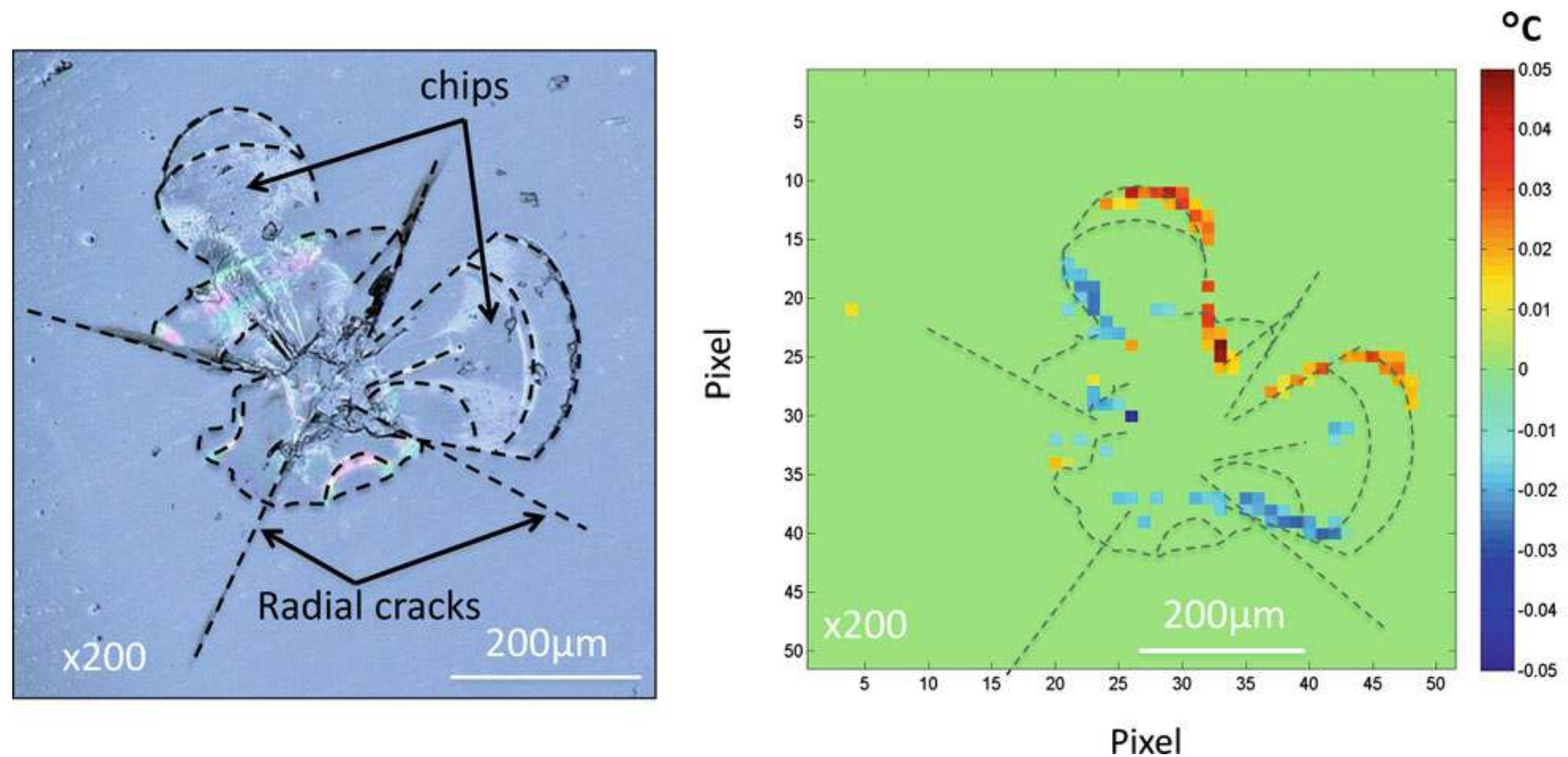

Fig. 4.7 Detection of thermal activity of imprint during a Brasilian test

equal to room temperature during the test. The thermal emissivity of the material is close to 1 ( $>0.84$ for soda lime glass). The spatial resolution was such that the size of the pixel was equal to $0.015 \mathrm{~mm}$, which is the size of the IR detectors. In order to ensure that the internal temperature of the camera was stabilized before performing the measurements, it was switched on $4 \mathrm{~h}$ before the experiment. Then, the Non Uniformity Correction (NUC) was performed by using the manufacturer's protocole. Once the temperature field at the specimen surface was stabilized, the temperature measurement was started.

\subsubsection{Experimental Results}

Figure 4.7 presents the superposition of temperature variation field obtained for the maximum of the cyclic force applied to the ring with the STFFT filter during first step.

Thermal activity was detected along the chips border, not at the tip of the radial cracks. The fact that no thermal activity was detected at the tip of the radial cracks does not mean that no stress variation occurred in these areas. Indeed, temperature variations are due to the variations of the sum of the principal Cauchy stresses, this is the basis of TSA (thermoelastic stress analysis [1]). So, if the mechanical loading induces a variation in the sum of the principal Cauchy stresses at the tip of the radial cracks, temperature variation will be detected. If the Cauchy stress tensor is mainly composed by a deviatoric part, a stress variation exists but does not induce temperature variation. In the present case, the only conclusion is that there is a variation in the sum of the principal Cauchy stresses at the chip's borders, not at the tip of the radial cracks.

\subsection{Conclusion}

In this study, a denoising methodology has been proposed to improve the spatial resolution of infrared images. The methodology is composed of two steps which consist first in removing the noise of the temporal signal at each pixel and second in shifting the residual offset value, which is different from one pixel to another. Results show that the approach is effective at preserving the spatial resolution of infrared images equal to 1 pixel, contrarily to the traditional spatio-temporal approach. By applying this denoising methodology to an imprint zone at the surface of a soda lime glass submitted to mechanical loading, results showed that thermal activity was detected in the chip zones. Negative and positive temperature variations were measured simultaneously, meaning that at a given time during the mechanical test, chips are submitted to very different loading conditions. The results obtained with this denoising methodology are promising and opennew ways of 
investigation to determine temperature variation fields in case of low signal-to-noise ratio. This is particularly valuable for understanding the thermomechanics of glassy materials, since stresses and heat sources in an imprint zone can henceforth be determined from accurate temperature field measurements.

Funding Information This work has received the financial support of AIS Scientific Grant from Rennes Métropole (2012), Mission of Resources and Skills Technology (MRCT) Grant from French National Center for Scientific Research (2012), Mission for Interdisciplinary (MI) Grant from French National Center for Scientific Research (2013), "Politiquedoctorale" Grant from Rennes 1 University (2013).

Acknowledgments The authors thank Dr. Laurent Calvez and Dr. Jean-Pierre Guin for fruitful discussions.

\section{References}

1. Dulieu-Barton, J., Stanley, P.: Development and application of thermoelastic stress analysis. journal of strain analysis for engineering design. J. Strain Anal. Eng. Des. 33, 93-104 (1998)

2. Chrysochoos, A., Maisonneuve, O., Martin, G., Caumon, H., Chezeau, J.O.: Plastic and dissipated work and stored energy. Nucl. Eng. Des. 114, 323-333 (1989)

3. Chrysochoos, A., Louche, H.: Thermal and dissipative effects accompanying luders band propagation. Mat Sci Eng A-struct. 307, 15-22 (2001)

4. Berthel, B., Wattrisse, B., Chrysochoos, A., Galtier, A.: Thermoelastic analysis of fatigue dissipation properties of steel sheets. Strain. 43, 273-279 (2007)

5. Pastor, M.L., Balandraud, X., Grédiac, M., Robert, J.L.: Applying infrared thermography to study the heating of 2024-t3 aluminium specimens under fatigue loading. Infrared Phys. Technol. 51(6), 505-515 (2008)

6. Wattrisse, B., Chrysochoos, A., Muracciole, J., Nmoz-Gaillard, M.: Analysis of strain localization during tensile tests by digital image correlation. Exp. Mech. 41, 2939 (2001)

7. Samaca Martinez, J.R., Le Cam, J.-B., Balandraud, X., Toussaint, E., Caillard, J.: Thermal and calorimetric effects accompanying the deformation of natural rubber. Part 1: thermal characterization. Polymer. 54, 2717-2726 (2013)

8. Samaca Martinez, J.R., Le Cam, J.-B., Balandraud, X., Toussaint, E., Caillard, J.: Thermal and calorimetric effects accompanying the deformation of natural rubber. Part 2: quantitative calorimetric analysis. Polymer. 54, 2727-2736 (2013)

9. Harris, J., Chiang, Y.-M.: Nonuniformity correction of infrared image sequences using the constant-statistics constraint. IEEE Trans. Image Process. 8, 1148-1151 (1999)

10. Le Cam, J.-B., Robin, E., Balandraud, X., Toussaint, E.: A new experimental route in thermomechanics of inorganic glasses using infrared thermography. J. Non-Cryst. Solids. 366, 64-69 (2013)

11. Robin, E., Le Cam, J.-B., Balandraud, X., Toussaint, E., Brilland, L.: First steps towards the thermomechanical characterization of chalcogenide glass using quantitative infrared thermography. J. Non-Cryst. Solids. 391, 101-105 (2014)

12. Cook, R.F., Pharr, G.M.: Direct observation and analysis of indentation cracking in glasses and ceramics. J. Am. Ceram. Soc. 73, 787-817 (1990)

13. Honorat V.: Analyse thermomcanique par mesure de champs des élastomères, Ph. D. thesis, Sciences et techniques du Languedoc. Montpellier, Universit Montpellier 2 (2006)

14. Poncelet M.: Multiaxiality, material and stress heterogeneities of self heating tests and high cycle fatigue tests, Ph. D. thesis, Ecolenormalesup'erieure de Cachan -ENS Cachan (2007)

15. Scribner, D., Kruer, M., Gridley, C., Sarkady, K.: Measurement, characterization, and modeling of noise in staring infrared focal plane arrays. In: Technical Symposium Southeast, International Society for Optics and Photonics, pp. 147-160. SPIE 0782, Orlando (1987)

16. Perez, F., Pezoa, J.E., Figueroa, M., Torres, S.N.: Empirical frequency do-main model for fixed-pattern noise in infrared focal plane arrays. Infrared Phys. Technol. 67, 413-426 (2014)

17. Schulz, M., Caldwell, L.: Nonuniformity correction and correctability of infrared focal plane arrays. Infrared Phys. Technol. 36(4), 763-777

18. El Gamal, A., Fowler, B.A., Min, H., Liu, X.: Modeling and Estimation of fpn Components in cmos Image Sensors. International Congress Proceeding, pp. 168-177. SPIE 3301, San Jose (1998)

19. López-Alonso, J.M., Alda, J., Bernabeu, E.: Principal-component characterization of noise for infrared images. Appl. Opt. 41(2), 320-331 (2002)

20. Zhao W., Zhang C.: Efficient scene-based non-uniformity correction and enhancement. In: Image processing, 2006 IEEE International Conference on, pp 2873-2876 (2006)

21. Zhao, W., Zhang, C.: Scene-based non-uniformity correction and enhancement: pixel statistics and subpixel motion. J. Opt. Soc. Am. A. 25(7), 1668-1681 (2008)

22. Guadagnoli E., Giunti C., Mariani P., Olivieri M., Porta A., Sozzi B. Zatti S.: Thermal imager non-uniformity sources modeling. In: Proc. SPIE, 8014, 80140A-80140A-12 (2011)

23. Medina O.J., Pezoa J.E., Torres S.N.: A frequency domain model for the spatial fixed-pattern noise in infrared focal plane arrays. In: Proc. SPIE, 8155, 81550H-81550H-9 (2011) 